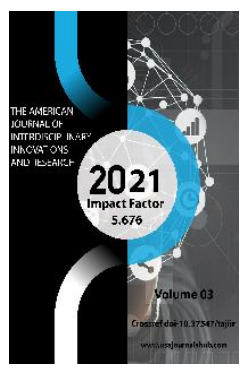

Copyright: Original content from this work may be used under the terms of the creative commons attributes 4.0 licence.

\section{Pedagogical Approaches To Educating Future Actors}

\author{
Shamsiddin Usmonov \\ Professor, Fergana Regional Branch Of Uzbekistan State Institute Of Arts And Culture, \\ Uzbekistan \\ Umidaxon Boltaboeva \\ Senior Lecturer, Fergana Regional Branch Of Uzbekistan State Institute Of Arts And Culture, \\ Uzbekistan \\ Nilufarxon Rahmonova \\ Lecturer, Fergana Regional Branch Of Uzbekistan State Institute Of Arts And Culture, \\ Uzbekistan \\ Toshpulat Akbarov \\ Associate Professor, Fergana Regional Branch Of Uzbekistan State Institute Of Arts And \\ Culture, Uzbekistan
}

\title{
ABSTRACT
}

This article tells the story of pedagogical approaches, art and stage secrets in educating future actors. Also, the role of culture and art in the socio-spiritual life of our people, the moral and ethical upbringing of the actor, the peculiarities of theatrical art, the need to pay special attention to the education of students in all its positive qualities from the first year; it is narrated that the educator must always be in the spotlight, from the way he dresses, to the way he shaves his hair, to the way he behaves in school, to the way he behaves.

\section{KEYWORDS}

Student, actor, director, imagination, upbringing, theater, etiquette.

\section{INTRODUCTION}

Our first president I.A.Karimov noted that education of young people today is an important task at the level of state policy, he also emphasized that we are talking about 
awakening, about self-awareness, about educating people in the spirit of national and universal values.

Indeed, today teachers need to teach students self-discipline, self-criticism, which is one of the most powerful motivators for selfdevelopment and self-realization.

The activity, awareness and commitment of students encourage them, first of all, to protect their health, patiently and contentedly manage their will and desires.

Ensuring that students have clear life goals, a clear vision of what they will do in the future, and an understanding that they will find their place in life through their aspirations and actions, and not take a random position in life this must be an important challenge for educators.

It's hard to find any profession or specialty in this life that isn't related to culture and the arts. If the builder is civilized, he will do his job artistically.

When a teacher reaches perfection, he leads his students to the highest heights of spirituality. Culture and art figures, creative intellectuals determine the spiritual and moral image of the nation, make an important contribution to the correct formation of public opinion on this or that issue.

It should be noted that the role of culture and art in the socio-spiritual life of our people is invaluable.This sphere reflects the heart and soul of people, their cares, dreams and aspirations, love and devotion to the Motherland, has a wide range of influence, is of incomparable importance in the development of human education and spirituality.
That is why our teachers take a very responsible approach to the process of educating students in the universities of arts and culture. It is said from the very beginning that the stage is a sacred place and should be respected. Entering the stage, realizing creative ideas and attracting the attention of the public requires great skill. That is why the relationship between teachers and students in art and culture universities is very different from other educational institutions.

That is, in our case, the distance between the student and the teacher, the border between them should be much thinner. We treat students like close friendsor their parents. As our sphere is connected with the human heart. If we move away from them or keep our distance, it will be more difficult for students to discover their talent. Our profession requires us to be very close to our students in order to create the right conditions for them to show their abilities, so that they become worthy people of our time.

The tongue and body of the artist are like the delicate strings of a tanbur.The actor must cleanse himself of any disgustingand inappropriate habits.

The role of a leader among members of staff responsible for creating a morally and spiritually healthy environment in the creative community is of particular importance, because a leader in art and culture universities is a leader of the creative team.

If you look at the life of great actors, they stood out from the crowd with their manners, ability to behave in public, sincerity, humility and kindness. 
Abror Khidoyatov, Olim Khodjaev, Shukur Burkhanov, Sora Eshonturaeva, Vohid Kadyrov, Manzura Khamidova, Razzok Khamroev were such modest, meek and humane people.

One of the main and important tasks of the theater school is to form the artistic level of students.An actor, professional or amateur, ultimately serves the public.Just how impressive, natural the performance is, how shocking the audience can be, can divide acting into professional and amateur levels.Usually, when we talk about a musician's skill, we evaluate his skill based on how well he has mastered the technique of playing the instrument. Acting is also rated based on how well you have mastered your acting technique.

Simple sketches are based on the first elements of mastery: sight, hearing, perception, smell, taste.On the other hand, the future actor or director must be able to observe life, to take from it the aspects he needs.Because theater is a reflection of life on stage. As long as a theatrical actor appears on stage in front of an audience of thousands as a model, not only the interpretation of the role he plays, but even the tone of the actor's speech is of great importance. Therefore, the spiritual image, behavior, clothing culture of future actors also play an important role in such a responsible work as educating the citizens of our independent republic in the spirit of national independence.

Each art school has two important tasks related to the education of students.

1. Formation of the student as a creative person.

2. Revealing the inner potential of the student.
The first task is carried out through the political and ideological, disciplinary, spiritual, ideological education of the future artist (the formation of a worldview, moments of creative pleasure, the formation of a spiritual image, etc.).

The second task is accomplished through professional education, through the formation of a sense of creative personality in the student's mind.

The acting test is, in fact, also an exam in another related subject.Because the student demonstrates his abilities in every way in the process of creating an artistic image.

Unfortunately, in the learning process, students do not pay serious attention to theoretical lessons.Undoubtedly, the reason for this situation is the teachers who teach the secrets of mastery.

Because they are unable to better explain to students how important theoretical knowledge is during practical training. On the other hand, teachers of theoretical subjects cannot explain to their students that theory is closely related to practice.In the process of teaching future actors to teachers who are moving towards one of the two sides: practical and theoretical knowledge, it will be necessary to create a platform for their students so that they can get acquainted with both knowledge at the stage at which the creative process takes place.

One of the main and important tasks of the theater school is to form the artistic level of students. The education of an actor in the field of morality and etiquette depends, on the one hand, on the peculiarities of theatrical art, and on the other, on the fact that the actor is at the 
forefront of the ongoing ideological struggle as a warrior of peace.

The actor, as a fighter of the ideological front, must have a deep understanding of his responsibility to the nation and the state, to protect the interests of the independent Republic.

"The stage is a small place equal to thirty steps in length, twenty steps in width and its height is equal to the curtain," writes Georgy Tovstanogov.

- However, when the curtains of this space are opened, the past, the present and the future can fit in it ..."

This means that everyone who decides to serve in the way of theatrical art must fulfill his honorable duty as a child of this country, with a deep understanding of his responsibility to the audience, the theater team, the playwright, the stage partner and, finally, his conscience.

Another unique aspect of theatrical art stems from its synthetic nature.That is, the fact that it operates on the basis of a single program as a collection of people from each field, is a complex team associated with the correct definition of the creative process, complicates the work of the theater.

The main tool of the actor's work is his emotional memory.The actor's life experience and strong intellectual memory help him to fully reveal the inner world of the character he wants to create.

If the future actor does not understand and master the qualities of teamwork, the importance of supporting colleagues, does not put the interests of the team above his own interests, does not master such qualities as honesty and decency in the educational process, he will have neither the time nor the opportunity to study these qualities on stage of the professional theater. Superficial imitation on stage by its appearance cannot distract the discerning viewer. Until the actor's mind develops the qualities of positive morality and decency, he will not be able to reflect the negative image convincingly. There is a saying among our people: "Innocent is the Creator." But when a person strives to get rid of his shortcomings and defects, it is a sign of his perfection.

As our grandfather Navoi said:

Not everyone is good at the world,

Not everyone's work is marginal.

An actor who is able to overcome the disadvantages of theatrical art at an early stage should devote his life to this complex field of art.Stepping on the threshold of this magical and mysterious world, called the theater, a person must leave all his vices and go inside. According to Vakhtangov, it is necessary to find qualities in the internal and external state of the actor that are not related to the theater, because it is necessary to study all the human qualities in the actor. That is, the educator must be able to form a creative team of each student, under his strong will, emotional influence

In such a creative environment, among the creative team led by a teacher who is able to lead their students to the path of ideas, profession, each student breathes easily, feels kindness and sincerity. As a result, each potential owner seeks to improve his abilities, skills, and expand his capabilities. 
Unfortunately, in recent years, more and more young people in theater schools and colleges are replacing the concepts of "independence and democracy" with concepts of shamelessness, obscenity, arrogance, and indiscipline.

In this regard, we would like to mention the following verse of Sheikh Saadi:

In fact, if the ability exists

Education is a work that makes it.

No matter how hard you try,

Iron is not actually an ore.

That remains the donkey of Jesus

Even if he goes to Mecca

Therefore, the student should pay special attention to the development of all the positive qualities in him from the first year.From how he dresses, to how he brushes his hair, how he behaves in school, how he behaves in society, he should always be in the care of a teacher.

If from afarit is immediately clear that the walking person is an actor or actress, and in addition to everything he boasts of his beauty and clothes, then he is not worth a dime as an actor or actress. The atmosphere in the theatrical world is such that not only beautiful flowers but also weeds can grow there. The soil of these conditions nourishes both selfless and diligent people who are true to their profession, who take personal pleasure from the path of art, and those who sacrifice art for their own interests.Aren't such fake artists the reasons why there is a low regard for actors among certain segments of the population?The responsibility to the art encourages every actor to look at his profession with respect.

If an actor wants to build confidence in his profession and the respect of others for him, he must start with himself first.

He must always remember the wise saying of the people, "Good manners are better than a thousand good garments." If behavior is one of the professional duties of an actor, then the direct responsibility of the director is to form the moral image of the creative team, to form a healthy creative environment. If in this branch of education, the director's ignorance and weakness are felt, it means that he is still far from perfect as a director.

It is worth noting that only in a spiritually healthy creative environment can a full-fledged artistic high performance be born.

This means that the director must not waste time and effort in forming a creative ethical environment in the theater. Because the time and effort spent will definitely pay off.

What kind of creative work can there be in a community where a spiritually healthy environment is not established, but where ugly vices such as laziness, idleness, apathy, carelessness, and heedlessness prevail?From this it follows that no matter how highly qualified a person is, if he does not pay attention to the criteria of morality in his work, his skill and high qualifications will not be able to save him from fiasco.

\section{REFERENCES}

1. Jura Mahmudov, Alphabet of stage composition, Tashkent-2006. 
2. Kholikulova G. Stage speech. Tashkent 2007

3. Boltaboeva U. Stage speech. Tashkent, INNOVATION-ZIYO, 2019.

4. Farfieva K. A. Social Media as a factor in formation of scientific thinking in youth. European Journal of Research and Reflection in Educational Sciences. Vol. 8 No. 10, 2020. - Pp. 52-56.

5. Farfieva, K. A. (2021). Theoretical Fundamentals Of Scientific And Innovative Thinking In Adolescents. The American Journal of Social Science and Education Innovations, 3(04), 431-437. 